\title{
Protective effect of total aralosides of Aralia elata (Miq) Seem (TASAES) against diabetic cardiomyopathy in rats during the early stage, and possible mechanisms
}

\author{
Shugang $\mathrm{Xi}^{{ }^{1 *} \text {, Guihua Zhou }}{ }^{3 *}$, Xuexin Zhang ${ }^{2}$, \\ Wenjie Zhang ${ }^{2}$, Lu Cai ${ }^{1,3,4,5}$ and Chunyan Zhao ${ }^{2,5}$ \\ ${ }^{1}$ Department of Endocrinology, at the First Hospital \\ ${ }^{2}$ Department of Physiology at the School of Basic Medical Sciences \\ Jilin University \\ Changchun 130021, China \\ ${ }^{3}$ Department of Medicine \\ ${ }^{4}$ Department of Pediatrics and Radiation Oncology \\ University of Louisville School of Medicine \\ Louisville, KY 40202, USA \\ ${ }^{5}$ Corresponding authors: Tel, 86-431-85619472; \\ E-mail, professorzhao@126.com (C. Zhao) \\ Tel, 1-502-852-2214; Fax, 1-502-852-5634; \\ E-mail, L0cai001@louisville.edu (L. Cai) \\ *These authors contributed equally to this work. \\ DOI 10.3858/emm.2009.41.8.059
}

\section{Accepted 4 March 2009}

Abbreviations: BG, blood glucose; CTGF, connective tissue growth factor; DAP, diastolic arterial pressure; DCM, diabetic cardiomyopathy; ECM, extracellular matrix; H\&E, hematoxylin and eosin; $I_{C a^{2+}-L}$, L-type $\mathrm{Ca}^{2+}$ channel current; $I_{t o}$, transient outward $\mathrm{K}^{+}$channel current; LV, left ventricular; LVEDP, left ventricular end diastolic pressure; LVSP, left ventricular systolic pressure; SAP, systolic arterial pressure; TASAES, total aralosides of Aralia elata (Miq) Seem

\begin{abstract}
Total aralosides of Aralia elata (Miq) Seem (TASAES) from Chinese traditional herb Longya Aralia chinensis $L$ was found to improve cardiac function. The present study was to determine the protective effects of TASAES on diabetic cardiomyopathy, and the possible mechanisms. Therefore, a single dose of streptozotocin was used to induce diabetes in Wister rats. Diabetic rats were immediately treated with low, medium and high doses of TASAES at $4.9,9.8 \mathrm{mg} / \mathrm{kg}$ and $19.6 \mathrm{mg} / \mathrm{kg}$ body weight by gavage, respectively, for eight weeks. Cardiac function was evaluated by in situ hemodynamic measurements, and patch clamp for the L-type $\mathrm{Ca}^{2+}$ channel current $\left(\mathrm{ICa}^{2+}-\mathrm{L}\right)$ and transient outward $\mathrm{K}^{+}$channel current $\left(\mathrm{l}_{\text {to }}\right)$. Histopathological changes were observed under light and electron microscope.
\end{abstract}

The expression of pro-fibrotic factor, connective tissue growth factor (CTGF) was monitored using immunohistochemistry staining. Compared with diabetic group, medium and high doses, but not low dose, of TASAES showed a significant protection against diabetes-induced cardiac dysfunction, shown by increased absolute value of left ventricular systolic pressure (LVSP) and maximum rates of pressure development $\left( \pm d p / d t_{m a x}\right)$, and enhanced amplitude of $I_{C^{2+}-L}$ $(P<0.05)$. Histological staining indicated a significant inhibition of diabetes-caused pathological changes and up-regulation of CTGF expression $(\boldsymbol{P}<$ $0.05)$. The results suggest that TASAES prevents diabetes-induced cardiac dysfunction and pathological damage through up-regulating $\mathrm{I}_{\mathrm{Ca}^{2+}-\mathrm{L}}$ in cardiac cells and decreasing CTGF expression.

Keywords: araloside; calcium channels, L-type; cardiomyopathies; connective tissue growth factor; diabetes mellitus; heart; hemodynamics; myocardium

\section{Introduction}

Diabetic cardiomyopathy (DCM), one of the major diabetic cardiovascular complications, has become a leading cause of the mortality in diabetic patients. DCM is characterized by its diastolic dysfunction and significant accumulation of extracellular matrix (ECM) (Fein et al., 1980; Fredersdorh et al., 2004). However its pathogenic mechanism is complex, and may be related to the changes of cardiac cell membrane ion channels, the $\mathrm{Na}^{+}-\mathrm{Ca}^{2+}$ exchange and the sarco(endo) plasmic reticulum $\mathrm{Ca}^{2+}$-ATPase function, and the induction of cardiac fibrosis (Chattou et al., 1999; Hattori et al., 2000; Zhao et al., 2006). For cardiac fibrotic responses to diabetes, attention has been paid recently to the role of connective tissue growth factor (CTGF) since several studies indicated the renal and cardiac fibrosis may not fully dependent on TGF- $\beta$, but may be predominantly dependent on CTGF (Way et al., 2002; Zhou et al., 2004). Therefore, an ideal approach to prevent DCM may target to manipulation of $\mathrm{Ca}^{2+}$ currents and CTGF expression.

Longya Aralia chinensis L., also named Aralia elata (Miq) Seem (AE), is Araliaceae aralia. It ge- 
nerally distributes in several provinces in China, including Liaoning, Jilin and Heilongjiang, Shandong, and Hebei provinces. It was also found in other countries, such as in Russia, Japan, and South Korea. Among the Aralia elata (Miq) Seems, chemical compositions are different according to the seasons when they grow and the parts where it is extracted. However, the contents are mainly in root and caudex bark. The root bark mainly contains saponin, as well as aetherolea, alkaloids, tannins, coumarin, and other components, amino acids and mineral elements (Dong, 1986). The leaves contain sinomenine sapogenin. Nine kinds of saponin ( $A, B, C, D, E, F, G, H, I)$ have been isolated from the root bark of Longya Aralia chinensis $L$ by thin-layer chromatography method. Total aralosides of Aralia elata (Miq) Seem (TASAES) are compounds extracted from aralia-

A

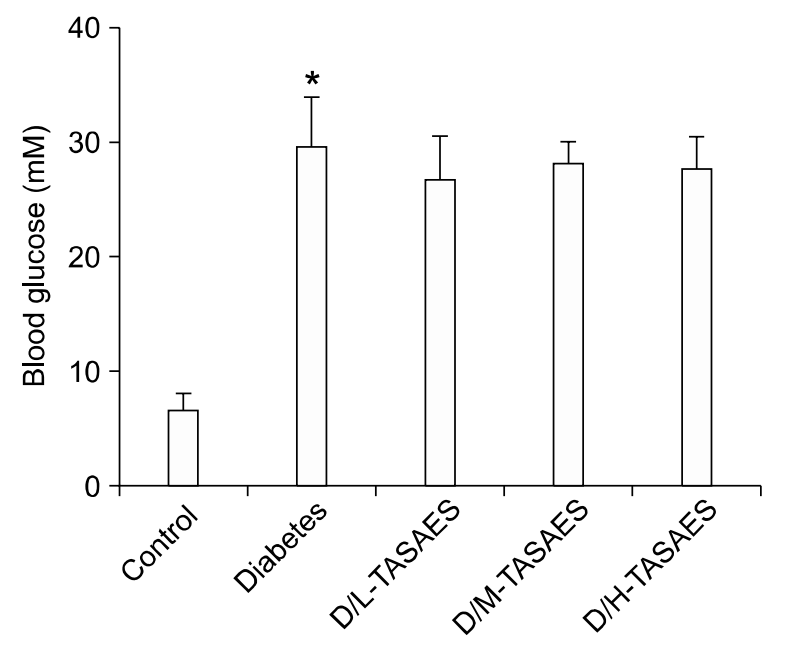

C

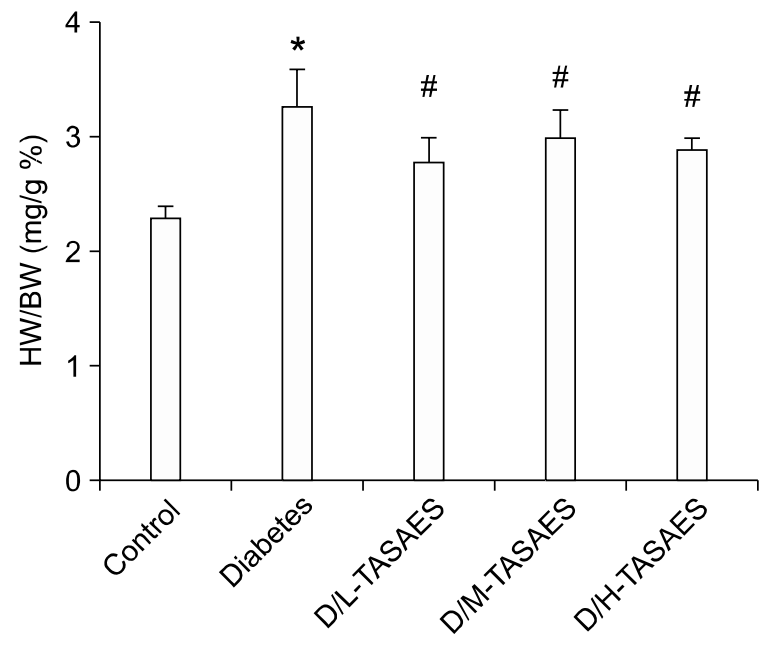

ceae aralia. Experimental studies in animal models have shown that TASAES could improve cardiac function. TASAES has the ability of anti-cardiac ischemia and anti-hypoxia as well as enhancing antioxidant enzyme activity (Zhou, 1991; Ge et al., 2001; Zhao et al., 2002) and increasing the concentration of free calcium in cardiac mitochondria (Liu et al., 2006).

However, there was no documentation for the protection of TASAES against diabetes-induced cardiac dysfunction to date. Therefore, the present study was to determine whether TASAES protects the heart from diabetes-induced cardiomyopathy in streptozotocin-induced diabetic rat model, by monitoring cardiac function using in situ hemodynamic measurements and examining histopathological changes under light and electron microscopes, and how TASAES prevents diabetic-induced cardio-

B

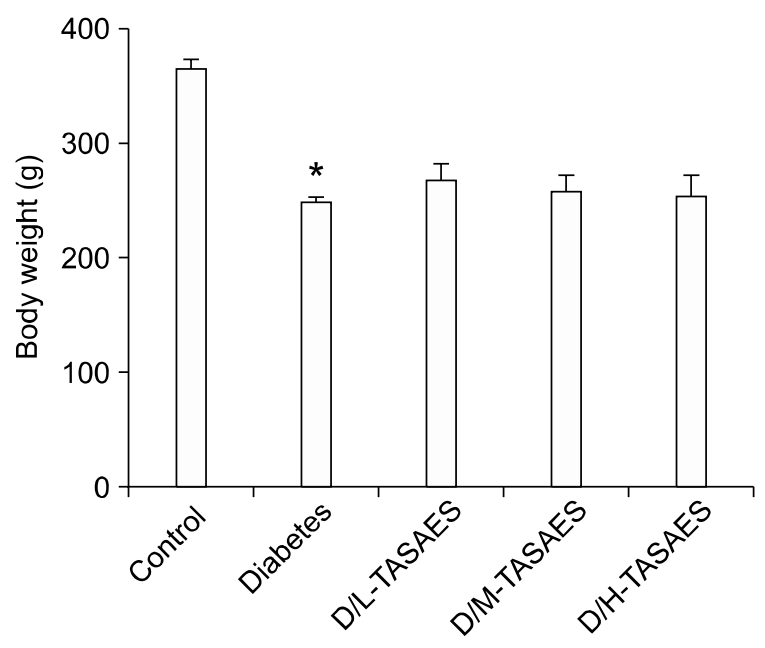

Figure 1. No effects of TASAES on the blood glucose and body weight in diabetic rats. Diabetic rats were induced with single injection of streptozotocin at $50 \mathrm{mg} / \mathrm{kg}$ body weight, and divided into four groups: Diabetes, D/L-TASAES, D/M-TASAES, and D/H-TASAES which were treated with sterile saline, $4.9 \mathrm{mg} / \mathrm{kg}, 9.8 \mathrm{mg} / \mathrm{kg}$, and 19.6 $\mathrm{mg} / \mathrm{kg}$ body weight TASAES, respectively, for 8 weeks. Blood glucose $(A)$ and body weight $(B)$ of the rats were monitored once a week. Heart weight $(\mathrm{C})$ was collected at eight weeks. Data represented were pooled from at least seven rats and presented as mean \pm SD. ${ }^{*} P<$ 0.05 vs Control, ${ }^{\#} P<0.05$ vs Diabetes. 
myopathy by measuring L-type $\mathrm{Ca}^{2+}$ channel current $\left(\mathrm{I}_{\left.\mathrm{Ca}^{2+}-\mathrm{L}\right)}\right.$ and transient outward $\mathrm{K}^{+}$channel current $\left(\mathrm{I}_{\mathrm{to}}\right)$ using patch clamp model, and pro-fibrotic mediator CTGF with immunohistochemical staining.

\section{Results}

\section{TASAES does not affect the blood glucose and body weight in the diabetic rats}

Diabetic rats were induced on day 3 after streptozotocin treatment, displaying whole blood glucose $(B G)$ levels higher than $16.7 \mathrm{mM}$ (Figure $1 \mathrm{~A})$. The $B G$ was significantly increased whereas body weight was decreased in diabetic rats compared with the control (Figure $1 \mathrm{~A}$ and $\mathrm{B}$ ), in consistent with our previous studies (Cai et al., 2002). Treatment with TASAES did not change either BG levels (Figure 1A) or body weight loss (Figure 1B), no matter at low and high dose levels. At eight weeks, the ratio of heart weight to body weight was increased in diabetic rats, indicating cardiac dysfunction, which were prevented by treatment with TASAES (Figure 1C).

\section{TASAES attenuates cardiac dysfunction in diabetic rats}

To determine the protection of TASAES on cardiac function, cardiovascular function was evaluated by LV hemodynamic analysis before rats were sacrificed (Table 1). Compared to control, diabetic rats showed significant decreases in systolic arterial pressure (SAP) and diastolic arterial pressure (DAP), which were attenuated by 8-week treatment of TASAES in a dose-dependent manner. Although treatment with TASAES at low dose did not significantly prevent diabetes-decreased left ventricular systolic pressure (LVSP), it significantly prevented diabetes-decreased left ventricular end dias- tolic pressure (LVEDP), absolute values of $\pm \mathrm{dp} / \mathrm{dt}_{\max }$ decline and heart rate (HR). At high dose, TASAES completely prevented diabetes-induced abnormalities of cardiac functions (Table 1).

\section{TASAES prevents morphological changes in the heart of diabetic rats}

Histological examination under light microscope with $\mathrm{H} \& \mathrm{E}$ staining showed that in the cardiac tissue of control rats, myocytes line up in order and its transverse striation was clear. The cellular nucleus was blue and there was no infiltration of inflammatory cells into the stroma (Figure $2 \mathrm{~A}$, upper row). In contrast, in the cardiac tissue of diabetic rats, there were severe necrotic cells with some heterophil granulocytes around them (Figure 2A). TASAES treatment for 8 weeks significantly prevented inflammatory and necrotic response in diabetic rats (Figure 2A, upper row).

Cardiac ultrastructural changes were also examined under electron microscope, which showed that the myofilaments line up in order in the cardiac tissue of control group. Mitochondrial ultrastructure was normal and line up closely in the heart of control rats (Figure 2A, lower row). However, myofilaments line up loosely and the structure of inocomma disappeared in the diabetic heart. Mitochondria were pyknic and its shapes were abnormal in the heart of diabetic rats (Figure 2A). High dose, but not low dose, of TASAES prevented cardiac ultrastructural changes in diabetic rats, indicating by closely lining up the myofilaments and almost normal structure of mitochondria (Figure 2A).

\section{TASAES attenuates diabetes-upregulated CTGF expression in the hearts of diabetic rats}

CTGF plays a pivotal role in fibrotic effects in diabetic complications (Way et al., 2002; Zhou et al., 2004). To determine effects of TASAES on

Table 1. Effects of TASAES on cardiovascular function in diabetic rats.

\begin{tabular}{lccccc}
\hline & Control & \multirow{2}{*}{ Diabetes } & \multicolumn{3}{c}{ Diabetes/TASAES } \\
\cline { 4 - 6 } & & & $4.9 \mathrm{mg} / \mathrm{kg}$ & $9.8 \mathrm{mg} / \mathrm{kg}$ & $19.6 \mathrm{mg} / \mathrm{kg}$ \\
\hline $\mathrm{SAP}(p / \mathrm{kPa})$ & $12.9 \pm 2.3$ & $8.4 \pm 2.6^{*}$ & $9.1 \pm 1.9$ & $9.5 \pm 1.8$ & $11.4 \pm 2.1^{\#}$ \\
$\mathrm{DAP}(p / \mathrm{kPa})$ & $7.4 \pm 1.4$ & $6.8 \pm 1.2$ & $6.9 \pm 1.6$ & $7.0 \pm 1.0$ & $7.6 \pm 1.4$ \\
$\mathrm{LVSP}(\mathrm{p} / \mathrm{kPa})$ & $14.8 \pm 1.0$ & $9.5 \pm 2.0^{*}$ & $10.1 \pm 1.6^{*}$ & $12.3 \pm 1.8^{\#}$ & $12.8 \pm 2.7^{\#}$ \\
LVEDP $(p / \mathrm{kPa})$ & $1.56 \pm 0.21$ & $2.41 \pm 0.33^{*}$ & $2.09 \pm 0.26^{\#}$ & $1.61 \pm 0.21^{\#}$ & $1.42 \pm 0.18^{\#}$ \\
$+\mathrm{dp} / \mathrm{dt}_{\max }(\mathrm{kPa} / \mathrm{s})$ & $320 \pm 52$ & $204 \pm 30^{*}$ & $229 \pm 43^{\#}$ & $278 \pm 45^{\#}$ & $308 \pm 34^{\#}$ \\
$-\mathrm{dp} / \mathrm{dt}_{\max }(\mathrm{kPa} / \mathrm{s})$ & $-265 \pm 34$ & $-166 \pm 32^{*}$ & $-211 \pm 27^{\#}$ & $-239 \pm 33^{\#}$ & $-256 \pm 40^{\#}$ \\
$\mathrm{HR}(\mathrm{beat} / \mathrm{min})$ & $395 \pm 41$ & $479 \pm 39^{*}$ & $457 \pm 37^{\#}$ & $440 \pm 40^{\#}$ & $434 \pm 37^{\#}$ \\
\hline
\end{tabular}

${ }^{*} P<0.05$ vs Control, ${ }^{\#} P<0.05$ vs Diabetes. 
cardiac fibrotic response to diabetes, expression of cardiac CTGF was examined by immunohistochemical staining (Figure 2B). The positive staining of CTGF was shown by brown particles in the interstitial and cytosol of myocytes. Semi-quantitative analysis by the average optical density of brown particles in the slides showed that there was a significant increase in cardiac tissue from diabetic rats (Figure $2 \mathrm{~B}$ ). TASAES treatment significantly prevented diabetes-caused up-regulation of CTGF at medium and high doses.

\section{Mechanisms of TASAES protection of the heart from diabetes}

To investigate the mechanisms by which TASAES protects the heart from diabetes-induced dysfunction, currents of calcium and potassium in the left ventricular (LV) myocytes were recorded using whole-cell patch clamp. Before recording the inward current of the LV cardiomyocytes, $2 \mathrm{mM}$ ATP and $5 \mathrm{mM}$ EGTA in the pipette solution was added to minimize rundown of $\mathrm{I}_{\mathrm{Ca}-\mathrm{L}}$ and low frequency stimuli. Currents were recorded after steady sealing for $5 \mathrm{~min}$. Tetrodotoxin, tetraethylammonium, 4-aminopyridine, and $\mathrm{CsCl}$ were used to block up $\mathrm{Na}^{+}$current, $\mathrm{I}_{\mathrm{k}}, \mathrm{I}_{\text {to }}$, and $\mathrm{K}^{+}$currents, respectively. The cardiomyocytes were depolarized from a holding potential of $-50 \mathrm{mV}$ for $400 \mathrm{mS}$ to $+60 \mathrm{mV}$ in steps of $+10 \mathrm{mV}$ at $1 \mathrm{~Hz}$ frequency. Ten cardiomyocytes were detected for $\mathrm{Ca}^{2+}$ inward current in each group. The I $\mathrm{Ca}_{\mathrm{C}-\mathrm{L}}$ amplitude was significantly

A

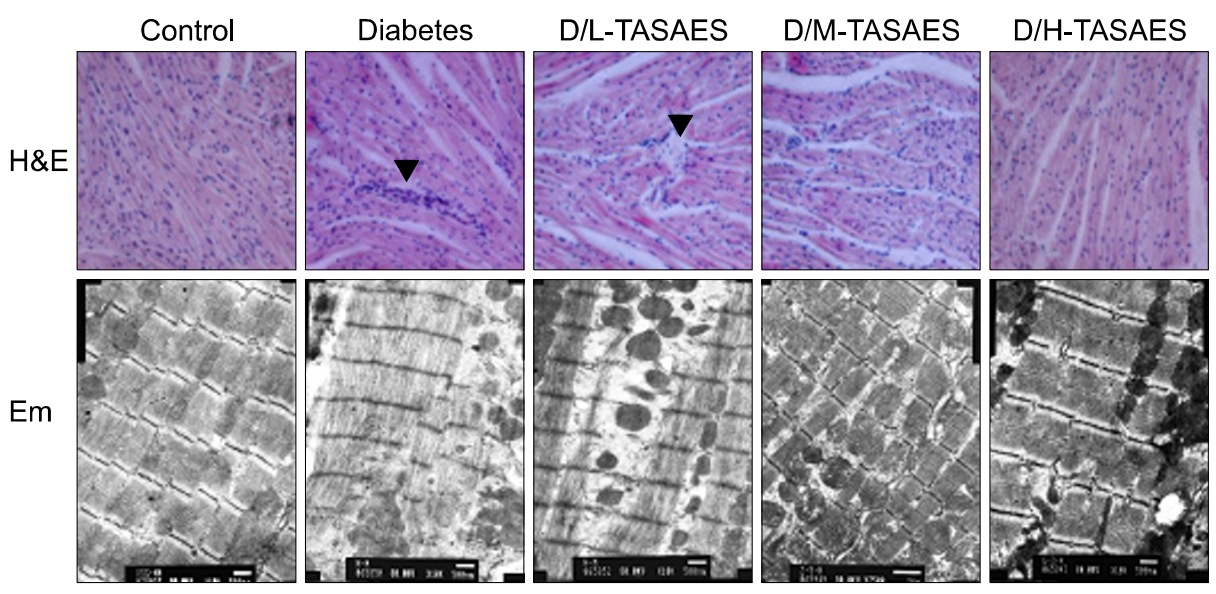

B
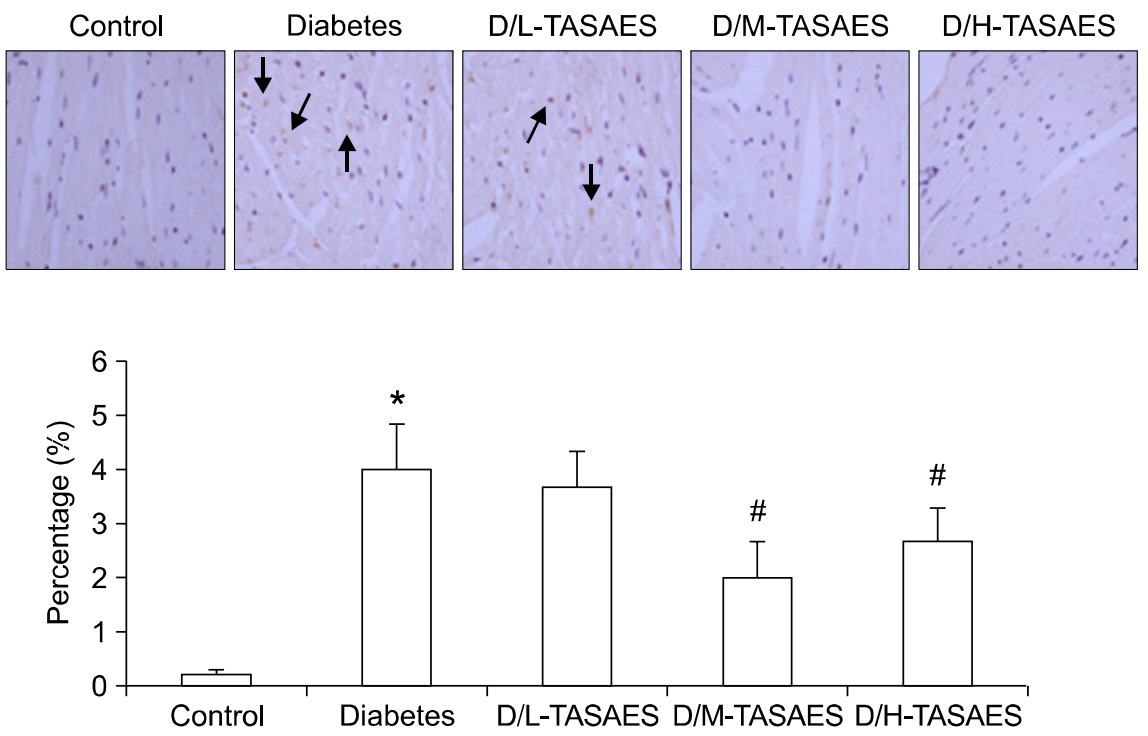

Figure 2. Effects of TASAES on the cardiac morphological changes and CTGF expression. Control and diabetic rats were treated with or without TASAES for eight weeks and sacrificed for histopathological examination and immunohistochemical staining. (A) Upper row, H\&E staining shows histopathological structure; lower row, electronic microscope examination shows cardiac ultrastructure. Arrow heads indicate infiltration of inflammatory cells. (B) CTGF immunohistochemical staining, with a semi-quantitative analysis from at lease seven rats. Arrows indicate CTGF positive staining. ${ }^{*} P<0.05$ vs Control, ${ }^{\#} P<0.05$ vs Diabetes. 
decreased in diabetic rats (Figure $3 \mathrm{~B}$ and $\mathrm{F}$ ). $\mathrm{Ca}^{2+}$ channels of two groups can be blocked up by Verapamil, their amplitudes are $0.67 \pm 0.00$ and $0.33 \pm 0.00(\mathrm{pA} / \mathrm{pF})$. I-V plot showed $\mathrm{Ca}^{2+}$ current activated at around $-50 \mathrm{mV}$ and peaked at about 0 $\mathrm{mV}$ (Figure 3G). Treatment with TASAES can dose-dependently increase the ICa-L amplitudes, suggesting that TASAES can completely prevent the intracellular change of calcium in diabetic hearts (Figure 3 ).

Change of $I_{\text {to }}$ in ventricular myocytes was also measured. When recording the voltage-dependent
$\mathrm{K}^{+}$outward current of the LV myocytes, $\mathrm{CdCl}_{2}$ was added in system to block up $\mathrm{Ca}^{2+}$ current and TTX to block up $\mathrm{Na}^{+}$current. Under this condition, the outward current would be ensured as pure $I_{\text {to }}$ current. In order to avoid the influence of natural attenuation in $\mathrm{K}^{+}$current, the $\mathrm{I}_{\text {to }}$ current amplitude of 10 cardiomyocytes were recorded within $20 \mathrm{~min}$, which has been ensured no significant attenuation. We randomly took $10 \mathrm{LV}$ cardiomyocytes for recording the $I_{\text {to }}$ currents and make sure that the primitive voltage curve whose potentials ranging from $-50 \mathrm{mV}$ to $+60 \mathrm{mV}$ in steps of $+10 \mathrm{mV}$ for 400
A

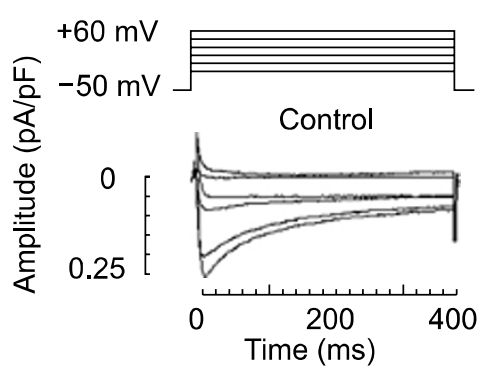

C

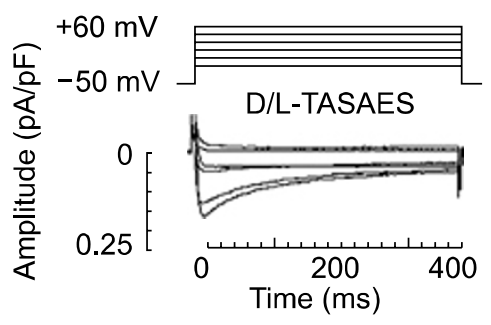

E

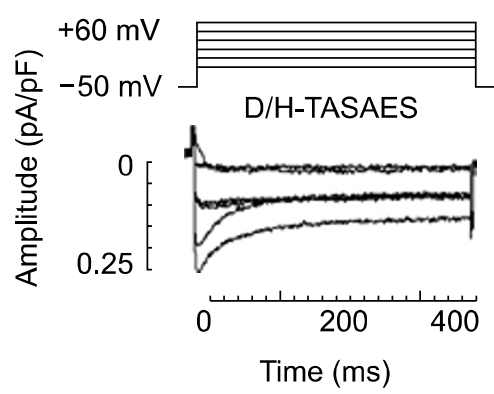

B

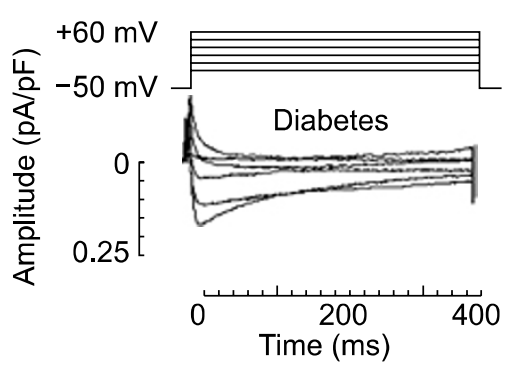

D

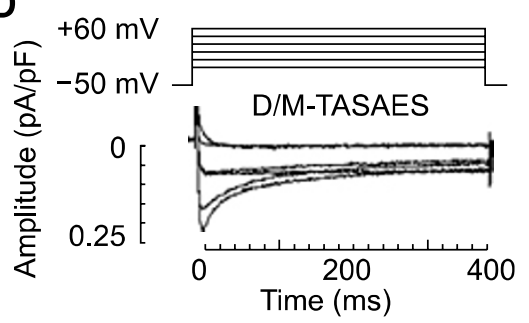

F

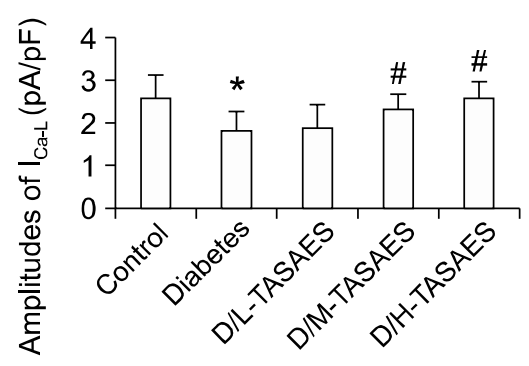

Figure 3. Effects of TASAES on the

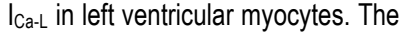
cardiomyocytes were isolated and whole cell patch were formed as described in Methods. Ten cardiomyocytes were recorded for $\mathrm{Ca}^{2+}$ inward current. The $\mathrm{I}_{\mathrm{Ca}-\mathrm{L}}$ amplitude was shown by the representative recordings for $I_{\text {Ca-L }}$ from control $(A)$, diabetes (B), D/L-TASAES (C), D/M-TASAES (D), and D/H-TASAES $(E)$. The quantitative data $(F)$ of the amplitudes of $\mathrm{I}_{\text {Ca-L }}$ from these groups were pooled from at least ten cardiomyocytes of each of the seven rats in each group. Data for I-V plot was also presented (G), showing $\mathrm{Ca}^{2+}$ current activated at $-50 \mathrm{mV}$ and peaked at $0 \mathrm{mV}$. ${ }^{*} P<0.05$ vs Control, ${ }^{\sharp} P<0.05$ vs Diabetes. 
$\mathrm{mS}$ at $1 \mathrm{~Hz}$ frequency.

Similar to ICa-L, Ito was significantly decreased in diabetes (Figure 4B). However, TASAES did not affect $I_{\text {to }}$ in diabetic rats no matter at low or high dose (Figure 4F). The I-V plot also showed that TASAES did not affect diabetic decrease in $I_{\text {to }}$ (Figure 4G).

\section{Discussion}

DCM is characterized by an early diastolic and later systolic dysfunction, with intracellular retention of calcium and sodium and loss of potassium (Mahgoub et al., 1998). Cardiac dysfunction occurs at six to twelve weeks even early at 2 weeks onset of diabetes. In our present study, cardiac presented the alternation of the diastolic function and contract function at 8 weeks, suggesting cardiomyocyte damage caused by diabetic hyperglycemia. H\&E staining showed the large area of necrosis in the heart of diabetic rats, indicated by nuclei flocculation or lysis with a great quantity of neutrophile granulocyte infiltration around necrotic
A

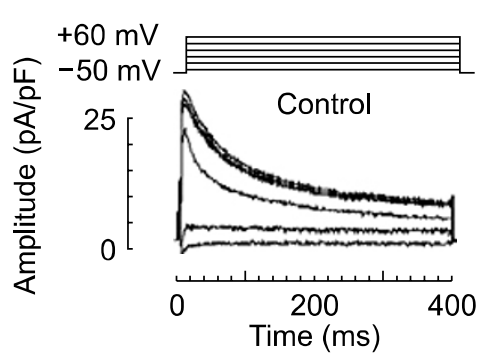

C

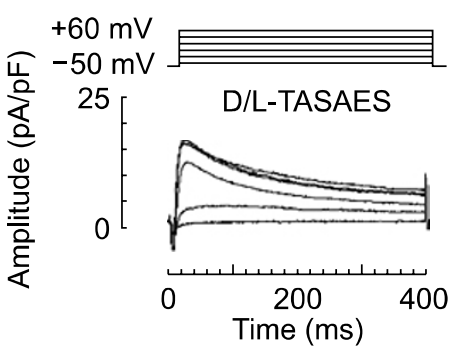

E

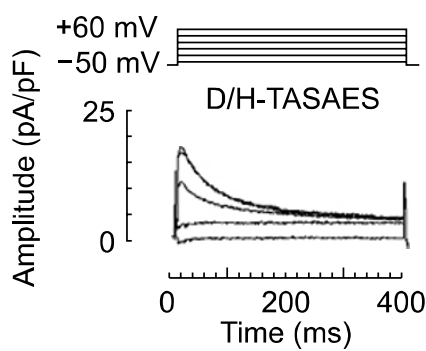

B

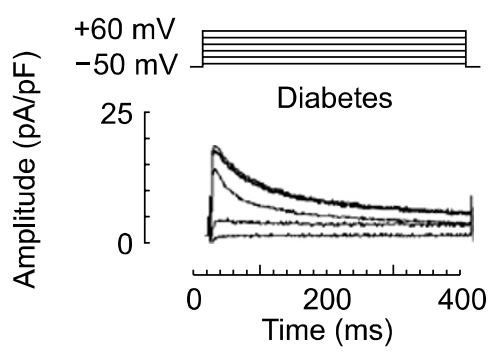

D

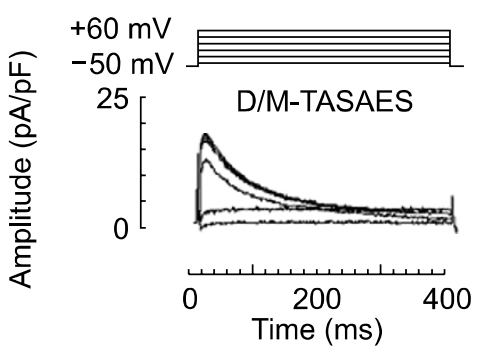

F

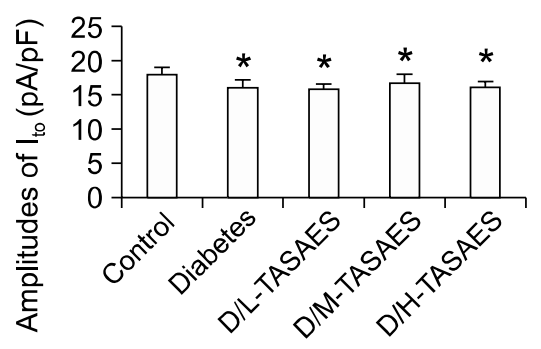

G

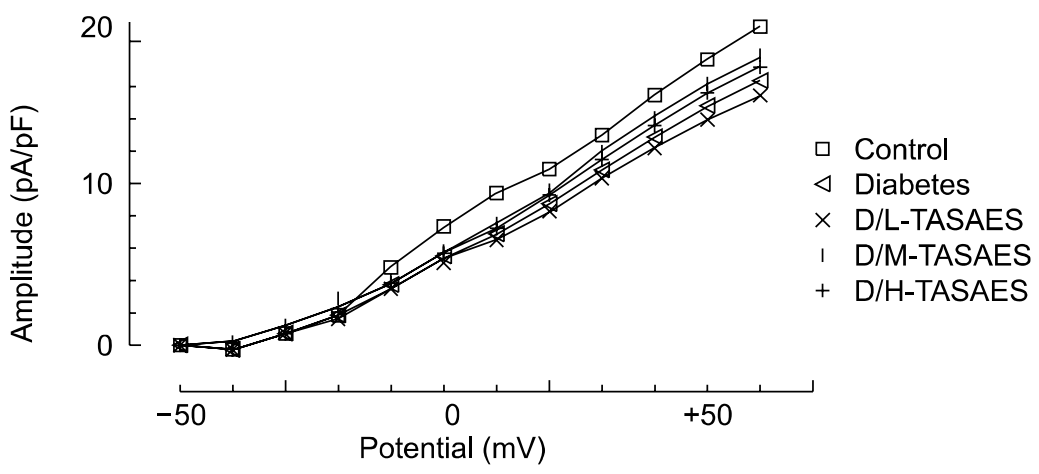

Figure 4. TASAES dose not affect $I_{\text {to }}$ in left ventricular myocytes. The cardiomyocytes were isolated and whole cell patch were formed as described in Methods. Ten cardiomyocytes were recorded for $\mathrm{K}^{+}$outward currents. The $I_{\text {to }}$ amplitude was shown by the representative recordings for Ito from control (A), diabetes (B), D/L-TASAES (C), D/M-TASAES (D), and D/H-TASAES (E). The quantitative data $(F)$ of the amplitudes of $I_{\text {to }}$ and I-V plot $(G)$ from these groups were pooled from at least ten cardiomyocytes of each of the seven rats in each group. ${ }^{*} P<0.05$ vs Control, ${ }^{\#} P<0.05$ vs Diabetes. 
cells. Treatment with TASAES attenuated necrosis in diabetes (Figure 2A). The ratio of heart weight to body weight (Figure 1C) indicated that the cardiac hypertrophy is quite obvious at 8 weeks (Figure $1 \mathrm{C})$. This is consistent with the impaired cardiac function (Table 1).

Myofilaments are puff and solvable, and the sarcomeres disappear in the heart of diabetic rats by cardiac ultrastructural observation (Figure 2A). Treatment with TASAES significantly prevented diabetes-caused myofilament damage and loses, and subsequently preserved the cardiac function (Table 1). The effects of TASAES at medium and high doses were more evident than that at low dose.

Several pathogenic factors contribute to DCM (Golfman et al., 1996; Ligeti et al., 2006). One of them is cardiac calcium transportation abnormality. Many studies have demonstrated that $\mathrm{I}_{\text {Ca-L }}$ in diabetic rat cardiomyocyte membrane was decreased. Therefore $I_{\text {Ca-L }}$ reduction possibly is one of the major causes for the cardiac dysfunction (Chattou et al., 1999; Yang et al., 1999). The calcium channel pause to the opening time extension will lead to more calcium inflowing under the identical voltage activation. Phosphorylation of calcium channel can open some channels that are inactive in normal situations (Lionel, 1998). Furthermore, alterations of cardiac sarcoplasmic reticulum $\mathrm{Ca}^{2+}$ -ATPase activity and $\mathrm{Na}^{+}-\mathrm{Ca}^{2+}$ exchanger activity that leads to calcium overload result in cardiac dysfunction in diabetic rats (Hattori et al., 2000; Zhao et al., 2006).

Experimental studies with animal models demonstrated that the prolonged action potential is resulted from the decreased outward repolarizing currents of potassium, especially transient outward potassium currents (Ito) (Qin et al., 2001). However its mechanism remains unclear. The electrocardiogram showed that the QT period was extended and the $T$ wave was low in diabetic cardiomyopathy. The $I_{\text {to }}$ was declined significantly in the condition of cardiac hypoxia, hypertrophy and heart failure (Cosis et al., 2004). It was reported that $I_{\text {to }}$ or $\mathrm{K}^{+}$channel expression decrease lead to the prolonged potential duration that can result in the calcium overload and arrhythmogenesis in type 1 diabetic rats (Shimon et al., 1994; Qin et al., 2001). Voltage-clamp studies of $I_{t o}$ in diabetic cardiomyopathy support a metabolic mechanism for $\mathrm{K}^{+}$ channel downregulation (Xu et al., 2002) since they found that when cardiomyocytes from type 1 diabetic rats were incubated with insulin in vitro for 2-4 $\mathrm{h}$, the density of $\mathrm{I}_{\text {to }}$ was recovered to the control level. These early studies suggest that insulin deficiency resulted in $I_{\text {to }}$ decrease, leading to cal- cium overload in type 1 diabetic heart. In the present study, however, TASAES did not affect the $I_{\text {to }}$ density in the cardiomyocytes from type 1 diabetic rats, suggesting that TASAES does not affect insulin-related glucose metabolism in the diabetic rats (Figure 1B). However, TASAES protected cardiac function along with a recovery of

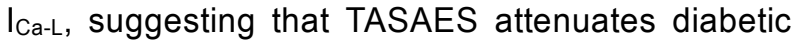
cardiac dysfunction mainly through regulating L-type calcium channel current, instead of potassium current.

CTGF, a cytokine discovered recently, has been demonstrated to play an important role in fibrotic response through a TGF- $\beta_{1}$-dependent or independent pathway (Way et al., 2002; Zhou et al., 2004). CTGF up-regulates ECMs, including collagen I, III, IV, fibrin and laminin and $\alpha_{5}$ integrin expression that enhance the cell and matrix interaction (Leask et al., 2002). The in vivo studies indicated that CTGF expression increased in many fibrosis disease models, suggesting that CTGF widely participates in ECM accumulation in the physiological or the pathological process (Leask et al., 2002; Candio et al., 2003; Chujo et al., 2005). Cardiac fibrosis can cause impairment of myocyte cell-to-cell communication, leading to cardiac dysfunction and arrhythmias.

Deng et al. (1988) treated rats with cardiac ischemia and infarction with TASAES at the dose of $5 \mathrm{mg} / \mathrm{kg}$ body weight, and found that TASAES significantly protected cardiac muscle from ischemia-caused damage, shown by decreasing creatine phosphokinase release, reducing the free fatty acid in plasma, and increasing superoxide dismutase activity in the heart. Our studies and others showed that TASAES has dose-dependent inotropic effects on the heart of diabetic rats. Furthermore, cardiomyocyte patch-clamp study and immunohistochemical staining demonstrated that TASAES ameliorate diabetes-caused cardiac dysfunction through regulating L-type calcium channels and inhibition of fibrotic factor CTGF expression. Previous studies demonstrated that the calcium transport abnormality and cardiac fibrosis can lead to DCM, and the decline of $I_{\text {Ca-L }}$ on cardiomyocyte membrane and cardiac fibrosis of diabetic rats can be the predominant cause of DCM (Way et al., 2002). Our studies suggested that TASAES probably increases $I_{\text {Ca-L }}$ on cardiomyocyte membrane and inhibits CTGF expression, and subsequently enhances cardiac contractility and protects cardiac function against diabetes.

The LD50 dose of TASAES is $39.2 \mathrm{mg} / \mathrm{kg}$; therefore, the highest dose of TASAES used in the present study is $19.6 \mathrm{mg} / \mathrm{kg}$ that is just half dose of LD50 dose. Both middle $(9.8 \mathrm{mg} / \mathrm{kg}, 1 / 4$ of LD50) 
and high $(19.6 \mathrm{mg} / \mathrm{kg})$ doses of TASAES effectively protected the heart from diabetes in terms of the most measurements without significant difference. This suggests that TASAES at the level of $1 / 4$ of LD50 can provide satisfactory protection against diabetic cardiomyopathy. Furthermore, TASAES was given by gavage, this Chinese medicine may be an alternative approach potentially used for diabetic patients to prevent the development of cardiac remodeling and dysfunction.

\section{Methods}

\section{Animal models}

Fifty male Wister rats (6 to 7 weeks old) were purchased from Experimental Animal Center of Jilin University. All animals were housed in the laboratory animal center for one week before starting the experiment. The rats with BG less than $7.0 \mathrm{mM}$ were chosen for the experiments, and were free access to rodent chow and tap water. All procedures have been approved by the University Animal Care and Use committee.

The rats were intraperitoneally given a single dose of streptozotocin (Sigma Chemical Co.) at $50 \mathrm{mg} / \mathrm{kg}$ body weight, dissolved in sodium citrate buffer $(\mathrm{pH} 4.5)$ after fasting for $12 \mathrm{~h}$ with free access to water. Control rats (Control) were given same volume of sodium citrate as described previously (Cai et al., 2002). On day 3 after streptozotocin treatment, whole blood was obtained from the tail-vein for detection of BG using a SureStep Complete Blood Glucose monitor (LifeScan, Milpitas, CA). Streptozotocin-treated rats with $B G$ higher than $16.7 \mathrm{mM}$ were considered diabetic.

Diabetic rats were randomly divided into four groups: diabetes (Diabetes), given sterile saline by gavage; low dose of TASAES group (D/L-TASAES), given TASAES at the dose of $4.9 \mathrm{mg} / \mathrm{kg}$ body weight by gavage; medium dose of TASAES group (D/M-TASAES), given with TASAES at $9.8 \mathrm{mg} / \mathrm{kg}$ by gavage; high dose of TASAES group (D/H-TASAES), given with TASAES at $19.6 \mathrm{mg} / \mathrm{kg}$ by gavage for 8 weeks. BG of the rats was monitored once a week.

\section{Assessment of left ventricular function}

Cardiac performance was assessed by using left ventricular (LV) hemodynamic analysis at eight weeks after diabetes, as described previously (Cai et al., 2005). Briefly, rats were anesthetized with $20 \%$ ethyl urethane $(\mathrm{C} 2 \mathrm{H} 5 \mathrm{CO} 2 \mathrm{NH} 2)$ at the dose of $0.5 \mathrm{ml} / 100 \mathrm{~g}$ body weight. After intubation of the trachea to maintain adequate ventilation, the right carotid artery was exposed and a micromanometer-tripped catheter (2-0; Millar SPR-249) was inserted and advanced into the LV. The catheter was secured around the artery. The other end was connected with the BL-420E organism functional experiment system by pressure transducer by which SAP and DAP were recorded. After $15 \mathrm{~min}$, stabilization of the heart function, LV pressure (LVSP and LVEDP), $+\mathrm{dp} / \mathrm{dt}_{\max }$ and decay (-dp/dtmax), HR were recorded.

\section{Isolation of left ventricular myocytes}

Hearts from rats were washed in the calcium Tyrode's solution (in $\mathrm{mM}: \mathrm{NaCl} 143 ; \mathrm{KCl} 5.4 ; \mathrm{CaCl}_{2} \cdot 2 \mathrm{H}_{2} \mathrm{O}$ 1.8; $\mathrm{MgCl}_{2} \cdot 6 \mathrm{H}_{2} \mathrm{O}$ 0.5; $\mathrm{NaH}_{2} \mathrm{PO}_{4} \cdot 2 \mathrm{H}_{2} \mathrm{O}$ 0.25; HEPES 5; Glucose $25 ; \mathrm{pH}$ 7.4). The heart was fixed in Langendorff and perfused with calcium Tyrode's solution for $1.5 \mathrm{~min}$, $\mathrm{Ca}^{2+}$-free Tyrode's solution (without $\mathrm{CaCl}_{2} \cdot 2 \mathrm{H}_{2} \mathrm{O}$ ) for $5 \mathrm{~min}$. enzyme solution $\left(\mathrm{Ca}^{2+}\right.$-free Tyrode's solution $+0.4 \mathrm{mg} / \mathrm{ml}$ collagenase $+0.1 \mathrm{mg} / \mathrm{ml}$ protease) for $7 \mathrm{~min}$. and stock solution (in $\mathrm{mM}$ : $\mathrm{KOH} 70$; L-glutamic 50 ; $\mathrm{KCl} 40$; Taurine 20; $\mathrm{KH}_{2} \mathrm{PO}_{4} 20 ; \mathrm{MgCl}_{2} \cdot 6 \mathrm{H}_{2} \mathrm{O}$ 3; Glucose 30; HEPES 10; EGTA 1.5; pH 7.4) for 5 min. The LVs were minced into pieces and incubated with stock solution with gently shake at $37^{\circ} \mathrm{C}$ for $10 \mathrm{~min}$. The cardiomyocytes were pelleted by centrifuging at $1,200 \mathrm{rpm}$ for $6 \mathrm{~min}$. The oxygen was given through the process of perfusion.

\section{Electrophysiological measurements}

Whole-cell patch clamp were used to analyze the L-type $\mathrm{Ca}^{2+}$ currents $\left(\mathrm{I}_{\mathrm{Ca}-\mathrm{L}}\right)$ and the transient outward $\mathrm{K}^{+}$currents $\left(I_{\text {to }}\right)$. The whole-cell recording pipettes (NARISHIGE DN-3, Japan) were perfused by pipette solution for $\mathrm{I}_{\mathrm{Ca}-\mathrm{L}}$ (in $\mathrm{mM}$ : CsCl 130; ATP 2; HEPES 5; EGTA 5; pH 7.3 adjusted with $\mathrm{CsOH}$ ) or pipette solution for Ito (in mM: $\mathrm{KCl} 140 ; \mathrm{MgCl}_{2} 1$; $\mathrm{CaCl}_{2}$ 1; EGTA 11; MgATP 5; $\mathrm{Na}_{2}$ ATP 5; HEPES 10; pH 7.2 adjusted with $\mathrm{KOH})$. The pipette resistance was in the range of 2 to $5 \mathrm{M} \Omega$ with internal solution. The standard external recording solution was as following (in $\mathrm{mM}$ ): tetraethyammonium-CL $135 ;$ 4-aminopyridine $5 ; \mathrm{MgCl}_{2}$. $6 \mathrm{H}_{2} \mathrm{O}$ 1; $\mathrm{CaCl}_{2} \cdot 2 \mathrm{H}_{2} \mathrm{O}$ 2; TTX 0.002; Glucose 30; HEPES 10; $\mathrm{pH}$ 7.4. The recording solution for $\mathrm{I}_{\mathrm{Ca}-\mathrm{L}}(\mathrm{mM}): \mathrm{NaCl} 145$; $\mathrm{CaCl}_{2} \cdot 2 \mathrm{H}_{2} \mathrm{O}$ 1.8; $\mathrm{MgCl}_{2} \cdot 6 \mathrm{H}_{2} \mathrm{O}$ 1.0; $\mathrm{CdCl}_{2}$ 0.1; TTX 0.002; Glucose 30; HEPES 10; pH 7.35. Using KCl $5.4 \mathrm{mM}$ instead of $\mathrm{NaCl}$ for $I_{\text {to }}$ recording solution when record $I_{\text {to }}$. The pipettes were put on the surface of the cardiomyocytes with propeller (NARISHIGE MO-102, Japan) and aspirated with the injector to form a negative pressure of $10-20 \mathrm{cmH}_{2} \mathrm{O}$. When they get in touch with the cardiomyocytes, it formed the high resistance seal ranging 1-5 $\mathrm{G} \Omega$ by attraction of negative pressure. The attraction of negative pressure was increased to make the local chaffs rupture. The pipette solution was connected with intracellular fluid and insulated with external solution. The whole-cell patch clamp recording system was formed. The recording was performed at room temperature. Currents were recorded using Clampex program in pClamp 6.01 (USA). Voltage-dependent currents were corrected for linear leak and residual capacitance by using an on-line $\mathrm{P} / 4$ subtraction. The current-voltage $(\mathrm{I}-\mathrm{V})$ curves were also recorded during the experiment.

\section{Light and electron microscope examination}

One-fourth of the hearts was immersion-fixed in $10 \%$ buffered formalin and embedded in paraffin for a light microscopic study. Two sections of $4 \mu \mathrm{m}$ thickness (an interval of $100 \mu \mathrm{m}$ ) per animal were stained with hematoxylin and eosin (H\&E) reagent. For electron microscope examination, the heart was cut into small pieces and 
prefixed in $2.5 \%$ glutaraldehyde $(0.2 \mathrm{M}$ cacodylate buffer, $\mathrm{pH} 7.4$ ) for $4 \mathrm{~h}$, post-fixed in $1 \%$ buffered sodium tetroxide for $1 \mathrm{~h}$ and embedded in Epon 812. Ultra-thin sections were examined using a JEM-1200 EX electron microscope.

\section{Immunohistochemical staining}

Heart tissue sections at $4 \mu \mathrm{m}$ were used to perform immunohistochemical staining for CTGF based on our previous method (Zhou et al., 2004; Song et al., 2005) with the following specific antibody: goat anti-rat CTGF antibodies (Santa Cruz Biotechnology, Santa Cruz CA). Color was developed by incubating with diaminobenzidine and counterstaining with hematoxylin. Controls were obtained by replacing the primary antibody with PBS. Semi-quantitative analysis of the percentage of positive staining area was evaluated by computer imaging analysis system (Image Proplus), as described previously (Zhou et al., 2004; Song et al., 2005).

\section{Statistical analysis}

Data were presented as mean \pm SD from at least seven samples. The overall $F$ test was performed to show the significance of the ANOVA models. The significance of the interactions and main effects was taken into consideration, and a proper method of pairwise comparison was chosen for each ANOVA. Differences between groups were considered significant at $P<0.05$.

\section{References}

Cai L, Li W, Wang G, Guo L, Jiang Y, Kang YJ. Hyperglycemia-induced apoptosis in mouse myocardium: mitochondrial cytochrome C-mediated caspase-3 activation pathway. Diabetes 2002;51:1938-48

Cai L, Wang J, Li Y, Sun X, Wan, L, Zhou Z, Kang YJ. Inhibition of superoxide generation and associated nitrosative damage is involved in metallothionein prevention of diabetic cardiomyopathy. Diabetes 2005;54:1829-37

Candio R, Forbe JM, Thomas MC, Thallas V, Dean RG, Burns WC, Tikellis C, Ritchie RH, Twigg SM, Cooper ME, Burrell LM. A breaker of advance glycation end products at attenuates diabetes-induced myocardial structural changes. Circ Res 2003;92:785-92

Chattou S, Diacono J, Feuvray D. Decrease in Sodiumcalcium exchange and calcium currents in diabetic rat ventricular myocytes. Acta Physiol Scand 1999;166:137-44

Chujo S, Shirasaki F, Kawara S, Inagaki Y, Kinbara T, Inaoki M, Takigawa M, Takehara K. Connective tissue growth factor causes persistent proalpha2(I) collagen gene expression induced by transforming growth factor-beta in a mouse fibrosis model. J Cell Physiol 2005;203:447-56

Cosis O, Echevarria E. Diabetic cardiomyopathy: electromechanical cellular alteration. Curr Vasc Pharmacol 2004;2: 237-48

Deng $H$, Li Y, Shen N. The protective effect of the total arasolides of aralia elata on experimental myocardial ischemia of rat heart. Chinese Journal of Pharmacology and Toxicology 1988;1:11-3

Dong WC. Determination of total aralosides in Aralia mandshurica grown in Jilin and Liaoning Provinces. Zhong Yao Tong Bao 1986;11:44-6.

Fein FS, Kornstein LB, Strobeck JE, Capasso JM, Sonnenblick EH. Altered myocardial mechanics in diabetic rats. Circulation Research 1980;47:922-33

Fredersdorh S, Thumann C, Ulucan C, Griese DP, Luchner A, Riegger GA, Kromer EP, Weil J. Myocardial hypertrophy and enhanced left ventricular contractility in zucker diabetic fatty rats. Circ Res 2004;13:11-9

Ge J, Guo C, Zhao C, Zhang X. Effect of Aralosides on rat hemodynamics. Journal of Norman Bethune University of Medcinal Sciences 2001;27:601-02.

Golfman LS, Takeda N, Dhalla NS. Cardiac membrane $\mathrm{Ca}^{2+}$-transport in alloxan-induced diabetes in rats. Diabetes Res Clin Pract 1996;31:s73-7

Hattori Y, Matsuda N, Kimura J, Ishitani T, Tamada A, Gando $S$, Kemmotsu O, Kanno M. Diminished function and expression of the cardiac $\mathrm{Na}^{+}-\mathrm{Ca}^{2+}$ exchanger in diabetic rats: implication in $\mathrm{Ca}^{2+}$ Overload. J Physiol 2000;527:85-94

Leask A, Holmes A, Abraham DJ. Connective tissue growth factor: a new and important player in the pathogenesis of fibrosis. Curr Rheumatol Rep 2002;4:136-42

Ligeti L, Szenczi O, Prestia CM, Szabó C, Horváth K, Marcsek ZL, van Stiphout, RG, van Riel NA, Op den Buijs J, Van der Vusse GJ, Ivanics T. Altered calcium handling in an early sign of streptozotocin-induced diabetic cardiomyopathy. Int J Mol Med 2006;17:1035-43

Lionel HO. The Heart Physiology, from Cell to Circulation, 1998, Lipincott-Raven Publishers

Liu J, Chang B. The Influence of A elata on the Free Calcium of the Rats' Cardiac Muscle Mitochondria during Overtraining. Journal of Tianjin University of Sport 2006;21: 423-25

Mahgoub MA, Abd-Elfattah AS. Diabetes mellitus and cardiac function. Mol Cell Biochem 1998;180:59-64

Qin D, Huang B, Deng L, EL-Adawi H, Ganguly K, Sowers $\mathrm{JR}$, El-Sherif $\mathrm{N}$. Down regulation of $\mathrm{K}^{+}$channel genes expression in type I diabetic cardiomyopathy. Biochem Biophys Res Commun 2001;283:549-53

Shimon Y, Firek L, Severson D, Giles W. Short-term diabetes alters $\mathrm{K}^{+}$current sin rat ventricular myocytes. Circ R 1994; $74: 620-28$

Song Y, Wang J, Li Y, Du Y, Arteel GE, Saari JT, Kang YJ, Cai L. Cardiac metallothionein synthesis in streptozotocininduced diabetic mice, and its protection against diabetesinduced cardiac injury. Am J Pathol 2005;167:17-26

Way KJ, Isshiki K, Suzuma K, Yokota T, Zvagelsky D, Schoen FJ, Sandusky PA, Vlaos CJ, Wakasaki H, King GL. Expression of connective tissue growth factor is increased in injured myocardium associated with protein kinase $C$ beta2 activation and diabetes. Diabetes 2002;51:2709-18 
Xu Z, Patel KP, Lou MF, Rozanski GJ. Up-regulation of K(+) channels in diabetic rat ventricular myocytes by insulin and glutathione. Cardiovascular Research 2002;53:80-8

Yang JM, Choic H, Ikory KA, Jang IS, Kim HW, Juhnn YS. Increased expression Galphag protein in the heart of streptocotocin-induced diabetes rats. Cardiovasc Res 1999; 31:129-34

Zhao C, Guo C, Zhang Y, Zhang X, Sun X, Sun Y. Positively inotropic effect of aralosides on isolated working rat heart. Journa of Norman Bethune University of Medical Science 2002;28:244-46
Zhao X, Hu S, Li J, Mou Y, Chen B, Xia Q. Decreased cardiac sarcoplasminc reticulum $\mathrm{Ca}^{2+}$-ATPase activity contributes to cardiac dysfunction in streptozotocin- induced diabetic rats. J Physiol Biochem 2006;62:1-8

Zhou G, Li C, Cai L. Advanced glycation end-products induce connective tissue growth factor-mediated renal fibrosis predominantly through transforming growth factor beta-independent pathway. Am J Pathol 2004;165:2033-43

Zhou Z. The anti-hypoxia function of aralosides. Chinese Traditional and Herbal Drugs 1991;22:114 